Open Access

\title{
Identification and characterization of laccase-type multicopper oxidases involved in dye-decolorization by the fungus Leptosphaerulina sp.
}

\author{
Ledys S. Copete ${ }^{1,2}$, Xiomara Chanagá ${ }^{1,2,3}$, Jorge Barriuso', María F. López-Lucendo ${ }^{1}$, María J. Martínez
} and Susana Camarero ${ }^{1 *}$

\begin{abstract}
Background: Fungal laccases are multicopper oxidases (MCOs) with high biotechnological potential due to their capability to oxidize a wide range of aromatic contaminants using oxygen from the air. Albeit the numerous laccase-like genes described in ascomycete fungi, ascomycete laccases have been less thoroughly studied than white-rot basidiomycetous laccases. A variety of MCO genes has recently been discovered in plant pathogenic ascomycete fungi, however little is known about the presence and function of laccases in these fungi or their potential use as biocatalysts. We aim here to identify the laccase-type oxidoreductases that might be involved in the decolorization of dyes by Leptosphaerulina sp. and to characterize them as potential biotechnological tools.

Results: A Leptosphaerulina fungal strain, isolated from lignocellulosic material in Colombia, produces laccase as the main ligninolytic oxidoreductase activity during decolorization of synthetic organic dyes. Four laccase-type MCO genes were partially amplified from the genomic DNA using degenerate primers based on laccase-specific signature sequences. The phylogenetic analysis showed the clustering of Lac1, Lac4 and Lac3 with ascomycete laccases, whereas Lac2 grouped with fungal ferroxidases (together with other hypothetical laccases). Lac3, the main laccase produced by Leptosphaerulina sp. in dye decolorizing and laccase-induced cultures (according to the shotgun analysis of both secretomes) was purified and characterized in this study. It is a sensu-stricto laccase able to decolorize synthetic organic dyes with high efficiency particularly in the presence of natural mediator compounds.

Conclusions: The searching for laccase-type MCOs in ascomycetous families where their presence is poorly known, might provide a source of biocatalysts with potential biotechnological interest and shed light on their role in the fungus. The information provided by the use of genomic and proteomic tools must be combined with the biochemical evaluation of the enzyme to prove its catalytic activity and applicability potential.
\end{abstract}

Keywords: Leptosphaerulina, Multicopper-oxidases, Laccases, Phylogeny, Secretome, Dye decolorization, Natural mediators

\footnotetext{
* Correspondence: susanacam@cib.csic.es

${ }^{1}$ Centro de Investigaciones Biológicas, CSIC. Ramiro de Maeztu 9, Madrid 28040, Spain

Full list of author information is available at the end of the article
}

C Biomed Central

(c) 2015 Copete et al. Open Access This article is distributed under the terms of the Creative Commons Attribution 4.0 International License (http://creativecommons.org/licenses/by/4.0), which permits unrestricted use, distribution, and reproduction in any medium, provided you give appropriate credit to the original author(s) and the source, provide a link to the Creative Commons license, and indicate if changes were made. The Creative Commons Public Domain Dedication waiver (http://creativecommons.org/publicdomain/zero/1.0/) applies to the data made available in this article, unless otherwise stated. 


\section{Background}

Multicopper oxidases (MCOs) are a multifaceted group of proteins with diverse functions, ranging from copper and iron metabolism (e.g. ceruloplasmin) to polyphenol oxidation (e.g. laccases), and different domain folding. Among MCOs, laccases, ascorbate oxidases, ferroxidases, bilirubin oxidases and pigment oxidases, organized in three cupredoxin-like domains, constitute the laccase-type group [1]. MCOs catalyze the oxidation of a wide variety of substrates with the concomitant reduction of molecular oxygen to water. There are different coordination modes for copper in MCOs: the Type 1 (T1), Type 2 (T2), and Type 3 (T3) copper centers that differ on their spectroscopic and EPR properties. In a typical MCO oxidation, the abstraction of four separate electrons takes place at the T1 copper site. Then, fast intramolecular electron transfer occurs from $\mathrm{T} 1$ site to the trinuclear $\mathrm{Cu}$ cluster (one T2 and two T3 copper ions) where oxygen binds and is converted to water.

Laccases typically show phenol oxidase activity. Besides, they oxidize a wide range of substituted aromatic amines, N-heterocycles, phenothiazines, thiol groups, etc. Laccases are found in vascular plants, fungi, bacteria, and insects, although the wood rotting and litter decomposing basidiomycete fungi are the main laccase producers. Laccases from white-rot fungi have been widely studied and characterized due to their role in lignin biodegradation. On the contrary, only a few ascomycete laccases (e.g. from Myceliophthora thermophila, Melanocarpus albomyces, Thielavia arenaria or Neurospora crassa) have been fully characterized, even though a number of laccase-like genes have been described in numerous ascomycetes so far [2, 3]. Fungal laccases are supposed to be involved in various physiological functions such as fruiting body development and pigmentation, copper homeostasis, or pathogenesis [4-6] in addition to their function in lignin degradation and plant litter decay processes [7, 8]. Nevertheless, further research effort is needed to assign concrete biological functions to the multiplicity of laccase-type MCOs of a fungal species.

The Dothideomycetes class of ascomycetes includes many important plant pathogens affecting all major crop plant families although Leptosphaerulina spp have been also described as saprophytes [9]. A variety of $\mathrm{MCO}$ genes has recently been discovered by the genome sequencing of different dothideomycetes fungi from the Pleosporales order: Leptosphaeria maculans which infects the oilseed rape [10], Pyrenophora tritici-repentis, a necrotrophic fungus causal to the disease tan spot of wheat (http://www.broadinstitute.org) and Phaeosphaeria (Stagonospora) nodorum which is also a pathogen of wheat (http://www.broadinstitute.org). However, little is known about the presence and function of laccases in the Dothideomycetes class or their potential use as biocatalysts.
Recently, an ascomycete strain from the Pleosporales order, isolated from lignocellulosic material in the Aburra Valley (Antioquia, Colombia), was selected due to its capability to decolorize different synthetic organic dyes. The identification of the fungus as Leptosphaerulina sp. was based on the sequence analysis of ITS1-ITS2 regions and $28 \mathrm{~S}$ rDNA and on morphological characteristics. The strain grown in malt extract plates showed ABTS oxidation activity, and laccase activity was detected as well during fungal decolorization of Reactive Black 5 in liquid cultures [11]. The sole information reported in years about the presence of laccases in Leptosphaerulina spp. dates back to 1979, when laccase was localized in the hyphae cell wall of Leptosphaerulina briosiana [12]. Recently, a laccase from Leptosphaerulina chartarum has been characterized as well [13].

We aim here to identify the laccase-type MCOs of this Leptosphaerulina strain by combing the use of genomic and proteomic tools and to characterize, by classical biochemistry methodologies, the laccases possibly involved in dye decolorization that could be useful as potential biotechnological tools.

\section{Methods}

\section{Microorganism and culture conditions}

Leptosphaerulina sp. CECT (20913) was isolated from lignocellulosic material in the Aburrá Valley (Colombia). The fungus was maintained in $2 \%$ malt extract agar. Liquid cultures were carried out in 1 L-flasks with $250 \mathrm{~mL}$ of medium containing glucose, ammonium tartrate, peptone and yeast extract [14]. When necessary the medium was supplemented with $200 \mathrm{mg} / \mathrm{L}$ of the azo dye Reactive Black 5; or with $500 \mu \mathrm{M} \mathrm{CuSO}_{4}$ and $9 \mathrm{~g} / \mathrm{L}$ ethanol as laccase inducers (laccase-inducing culture). Inocula consisted of $5 \mathrm{~mL}$ of mycelium grown for $15 \mathrm{~d}$ in malt extract under stationary conditions and homogenized in a Sorvall Omni-Mixer at $16,000 \mathrm{rpm}$ for $30 \mathrm{~s}$. Flasks were

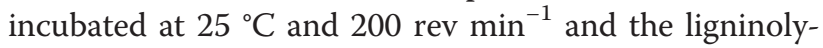
tic oxidoreductase activities secreted by Leptosphaerulina sp. were monitored for 16 days.

\section{Enzymatic assays}

The oxidation of $3 \mathrm{mM}$ ABTS (2,2-azino-bis(3-ethylbenzothiazoline-6-sulfonic acid) was followed the formation of the radical cation $\left(\varepsilon_{418}=36,000 \mathrm{M}^{-1} \mathrm{~cm}^{-1}\right)$ in $100 \mathrm{mM}$ sodium tartrate buffer $\mathrm{pH} 3$, in the absence or presence of $0.1 \mathrm{mM} \mathrm{H} \mathrm{H}_{2} \mathrm{O}_{2}$ to determine laccase and peroxidase activities, respectively. $\mathrm{Mn}^{2+}$ oxidation was followed at $\mathrm{pH} 5$ for the formation of $\mathrm{Mn}^{3+}$ tartrate complex $\left(\varepsilon_{238}=\right.$ $6,500 \mathrm{M}^{-1} \mathrm{~cm}^{-1}$ ). Dye oxidation were assayed at $\mathrm{pH} 3$ by monitoring the disappearance of $50 \mu \mathrm{M}$ Reactive Black 5 $\left(\varepsilon_{598}=30,000 \mathrm{M}^{-1} \mathrm{~cm}^{-1}\right)$ and $25 \mu \mathrm{M}$ Reactive Blue 19 $\left(\varepsilon_{595}=10,000 \mathrm{M}^{-1} \mathrm{~cm}^{-1}\right)$. Reactions were initiated by the addition of $0.1 \mathrm{mM} \mathrm{H}_{2} \mathrm{O}_{2}$. One enzymatic activity unit 
was defined as the amount of enzyme that oxidizes $1 \mu \mathrm{mol}$ of substrate in $1 \mathrm{~min}$.

\section{Production and purification of laccase}

The supernatant of a three-day culture supplemented with $500 \mu \mathrm{m} \mathrm{CuSO}_{4}$ and $9 \mathrm{~g} / \mathrm{l}$ ethanol, was centrifuged, filtered and concentrated by ultra filtration using a 5kDa cut-off membrane. The concentrated sample was precipitated with sulphate ammonium $(85 \%)$. The precipitate was centrifuged, dissolved in $20 \mathrm{mM}$ Bis-Tris buffer, $\mathrm{pH} 6.5$ and concentrated (Amicon 10-kDa-cutoff). The sample was then subjected to anionic-exchange chromatography using a Hi Trap Q FF $5 \mathrm{~mL}$ column (GE Healthcare) pre-equilibrated with $20 \mathrm{mM}$ Bis-Tris, $\mathrm{pH}$ 6.5, and connected to an AKTA Purifier System (Amersham Biosciences). Proteins were eluted with a 0 $25 \% \mathrm{NaC} 1 \mathrm{M}$ gradient, at $1.5 \mathrm{ml} / \mathrm{min}$ flow rate. Fractions with laccase activity were pooled, dialysed, concentrated and subjected to high-performance anion-exchange chromatography using a Mono Q 5/50 GL column (GE Healthcare) equilibrated with the same buffer. The retained proteins were eluted with a $0-6 \% \mathrm{NaCl} 1 \mathrm{M}$ gradient, at $0.5 \mathrm{ml} / \mathrm{min}$, and laccase fractions were pooled, dialysed and concentrated. The last purification step consisted of size-exclusion chromatography with a Superdex 75 FPLC column (Pharmacia). The protein was eluted with $0.15 \mathrm{M} \mathrm{NaCl}$ at $0.3 \mathrm{~mL} / \mathrm{min}$, dialysed and concentrated in Amicon Ultra-15 (Millipore).

\section{Laccase characterization}

Pure laccase $(6 \mu \mathrm{g}$ of protein) was deglycosylated with $15 \mathrm{mU}$ of endo- $\beta-\mathrm{N}$-acetylglucosaminidase $\mathrm{H}$ (Endo- $\mathrm{H}$ ) in $50 \mathrm{mM}$ sodium tartrate buffer, $\mathrm{pH} 5.5$, at $37^{\circ} \mathrm{C}$ overnight. Polyacrylamide electrophoresis under denaturizing conditions (SDS-PAGE) was performed at $7.5 \%(\mathrm{p} / \mathrm{v})$ and the protein bands stained with Coomassie Brilliant Blue. Laccase molecular mass was determined before and after deglycosylation by MALDI/TOF-TOF (Matrixassisted laser desorption/ionization-time of flight). Isoelectric point was determined by isoelectrofocusing electrophoresis with Criterion IEF Precast gel (Bio-Rad) using a $\mathrm{pH}$ range from 3 to 10 . The $\mathrm{UV}$-visible absorption spectrum of the enzyme was recorded in a Shimadzu spectrophotometer.

Kinetics for the oxidation of ABTS $\left(\varepsilon_{418}=36,000 \mathrm{M}^{-1}\right.$ $\left.\mathrm{cm}^{-1}\right)$ and 2,6-dimethoxyphenol $\left(\varepsilon_{469}=27,500 \mathrm{M}^{-1} \mathrm{~cm}^{-1}\right)$ were determined at $25^{\circ} \mathrm{C}$, in $0.1 \mathrm{M}$ sodium tartrate buffer $\mathrm{pH} 3$, using concentrations between 0 and $1 \mathrm{mM}$ ABTS and $0-5 \mathrm{mM}$ DMP. The kinetic constants were calculated from Michaelis-Menten equation in Sigma Plot Software. Optimum $\mathrm{pH}$ for laccase activity with ABTS and DMP was determined within a $\mathrm{pH}$ range of $2-9$ in $0.1 \mathrm{M}$ Britton and Robinson buffer. The stability of the enzyme against $\mathrm{pH}$ was calculated by the difference between the initial laccase activity and the activity remaining after 180 min of incubation in 0.1 M Robinson buffer at different $\mathrm{pH}(2-9)$. The thermal stability of the purified laccase was determined in a temperature range of $30-80{ }^{\circ} \mathrm{C}$, for $10 \mathrm{~min}$, in $0.1 \mathrm{M}$ sodium tartrate buffer $\mathrm{pH} 3$ with ABTS as substrate. All measurements were made in triplicate in a Versa Max Microplate Reader (Molecular Devices).

\section{Dye decolorization assays}

Enzymatic decolorization of synthetic organic dyes was assayed with $100 \mathrm{mU}$ of crude Leptosphaerulina sp. laccase in $0.1 \mathrm{M}$ sodium tartrate buffer $\mathrm{pH} 3$, at room temperature. The reaction mixture contained $50 \mu \mathrm{M}$ dye (except for Remazol Brillant Blue that was $100 \mu \mathrm{M}$ ) and, when necessary, double concentration of the following mediators: acetosyringone, syringaldehyde, methyl syringate or 1-hydroxybenzotriazole. Controls without enzyme were carried out in parallel. All measurements were performed in triplicate, after 0, 2, 3 and 4 hours, in the microplate reader. Dye decolorization was expressed in terms of percentage of the absorbance decrease at the maximum wavelength for each dye: Methyl Orange (azo-dye), $500 \mathrm{~nm}$; Reactive Black 5 (di-azo), $597 \mathrm{~nm}$; Evans Blue (di-azo dye), $605 \mathrm{~nm}$; Orange II (azo-dye), $484 \mathrm{~nm}$; Remazol Brilliant Blue (anthraquinone), $595 \mathrm{~nm}$; Acid Blue 74 (indigo), $609 \mathrm{~nm}$; and Aniline Blue (triphenylmethane), $583 \mathrm{~nm}$.

\section{Trypsin digestion and peptide analysis of the pure protein}

Pure laccase was digested with trypsin and the resulting peptides were analyzed by an LTQ-Orbitrap Velos mass spectrometer coupled to a nano Easy high-performance liquid chromatography (Thermo Sccientific). Peptides were trapped onto a C18-A1 $2 \mathrm{~cm}$ precolumn and then eluted onto a Biosphere C18 capillary column using solutions $\mathrm{A}$ and $\mathrm{B}$ ( $0.1 \%$ formic acid in pure acetonitrile) at a flow-rate of $250 \mathrm{~nL} / \mathrm{min}$ with the following gradient: 0-35 \% Buffer B, for 55 min and 35-45\% Buffer B, for 10 min. Full-scan MS spectra (m/z 300-1700) were acquired in the positive ion mode. The 15 most intense ions were selected for collision induced dissociation (CID) fragmentation. Mass spectra files were searched against Uniprot database (http://www.uniprot.org/) and The Laccase and multicopper oxidase Engineering Database (LccED, http://www.lcced.uni-stuttgart.de/cgi-bin/ LccED1.2/index.pl) using SEQUEST through Proteome Discoverer (version 1.4.1.14).

\section{Amplification of laccase-like genes}

Genomic DNA was extracted from fungal mycelium grown in malt extract liquid medium using DNeasy Plant Mini Kit (Qiagen). Laccase-like genes were amplified using degenerate primers based on the sequences of the conserved copper binding motifs L2 $(\mathrm{HXH})$ and L3 
(HXXHXH) of laccases from related ascomycete fungi (LAC2FOR 5'- GGIACIWIITGGTAYCAYWSICA -3' and LacL3Rv 5'- GTCGTGKCCGTGSARRTGGA -3'). A degenerate primer ( $\mathrm{Fw}$ 5'- GCWAAATGGGGYGACA CKATY -3') based on the 7 first amino acid residues of the peptide found in the proteomic analysis of the pure enzyme (AKWGDTI) was also used for the amplification of Leptosphaerulina sp. laccase genes from the genomic DNA. The amplification reactions contained $100 \mathrm{ng}$ of DNA template, $1.5 \mathrm{mM} \mathrm{MgCl} 2,0.8 \mathrm{mM}$ dNTPs, $0.5 \mu \mathrm{M}$ of each primer and $1 \mathrm{U}$ de Taq DNA polymerase (Invitrogen) in $50 \mu \mathrm{L}$ final volume. The amplification program was as follows: $3 \mathrm{~min}$ at $95{ }^{\circ} \mathrm{C}$; 30 cycles of $45 \mathrm{~s}$ at $95{ }^{\circ} \mathrm{C}$, followed by $45 \mathrm{~s}$ at $52{ }^{\circ} \mathrm{C}$ and $2 \mathrm{~min}$ at $72{ }^{\circ} \mathrm{C}$; and a extension step for $5 \mathrm{~min}$ at $72{ }^{\circ} \mathrm{C}$. PCR products were purified with the QIAquick Gel Extration Kit. The amplified sequences were cloned into pGEM-T easy cloning system (Promega) and transformed into Escherichia coli $\mathrm{DH} 5 \alpha$ cells. Clones containing the inserted fragments were screened by DNA sequencing using the BigDye Terminator v3.1 Cycle Sequencing kit. The nucleotide sequences were translated and the introns (one in lac3 from nucleotide 178 to 228 , and other in lac2 from nucleotide 133 to 180) were removed.

\section{Phylogenetic analysis}

Phylogenetic analysis for the four deduced amino acid sequences of Leptosphaerulina sp laccase-like proteins was based on MUSCLE multiple alignment with partial protein sequences (L2 to L3 length) from different types of fungal MCOs (basidiomycete laccases, ascomycete laccases, ascorbate oxidases, ferroxidases, fungal pigment oxidases). The evolutionary history was inferred using the Neighbor-Joining method. Bootstrapping was carried out with 1000 replications. The evolutionary distances were computed using the JTT matrix-based method. All positions containing gaps and missing data were eliminated. Evolutionary analyses were conducted in MEGA6. The tree was rooted by two insect laccase sequences.

\section{Secretome analysis and peptide analysis}

Crude extracts from liquid cultures supplemented with RB5 (after 7 days of incubation) or with copper and ethanol as laccase inducers (after 3 days of incubation) were filtered through $0.22 \mu \mathrm{m}$ membranes and concentrated by tangential ultrafiltration (Amicon 5-kDa-cut-off).

Sample impurities were removed by short PAGE stained with Colloidal Blue. Samples of around $5 \mu \mathrm{g}$ of protein [15] were dissolved in sample buffer $(37.5 \mathrm{mM}$ Tris- $\mathrm{HCl} \mathrm{pH}$ 8, 1.5 \% (w/v) SDS, 1 mM EDTA, $1.96 \mathrm{mM}$ DTT, $0.005 \%(\mathrm{w} / \mathrm{v})$ bromophenol blue and $12.5 \%(\mathrm{v} / \mathrm{v})$ glycerol) and run into a $12 \%$ SDS-gel. Excised bands were distained with $50 \mathrm{mM}$ ammonium bicarbonate, dehydrated with $50 \% \mathrm{ACN}$ and dried. The dried gel pieces were reduced with $10 \mathrm{mM}$ dithiothreitol for $30 \mathrm{~min}$ at $56{ }^{\circ} \mathrm{C}$, alkylated with $55 \mathrm{mM}$ iodoacetamide in obscurity for $30 \mathrm{~min}\left(24{ }^{\circ} \mathrm{C}\right)$ and digested with $12.5 \mathrm{ng} / \mu \mathrm{L}$ trypsin in $50 \mathrm{~mm}$ ammonium bicarbonate, overnight at $30^{\circ} \mathrm{C}$. Peptides were extracted at $37{ }^{\circ} \mathrm{C}$ using $100 \% \mathrm{ACN}$ and then $0.5 \%$ trifluoroacetic acid, dried, cleaned using ZipTip with $0.6 \mu \mathrm{L} \mathrm{C18}$ resin (Millipore).

The tryptic peptides were reconstituted in $5 \mu \mathrm{L}$ solution A ( $0.1 \%$ formic acid in $2 \%$ acetonitrile), and analyzed in the LTQ-Orbitrap Velos. The peptides from EPP digestions were eluted with a $0-45 \%$ Buffer B gradient, $210 \mathrm{~min}$. Full-scan MS spectra (m/z 300-1800) were acquired as aforementioned. Mass spectra files were searched against Uniprot and LccED databases as described above. Search parameters included a maximum of two missed cleavages allowed, carbamidomethylation of cysteines as a fixed modification and oxidation of methionine as variable modifications. Identified peptides were validated using Percolator algorithm [16]. Besides, an inhouse database was constructed with the partial laccasetype sequences of Lepthosphaerulina sp. disclosed in this study (Lac1-Lac4), to investigate the presence of these MCOs among the oxidoreductases secreted by the fungus under dye-decolorizing and laccase-inducing conditions.

\section{Results}

\section{Characterization of Leptosphaerulina sp. laccase}

Leptosphaerulina sp. was grown in liquid medium in the absence and in the presence of the azo dye Reactive Black 5. The fungus initiated dye decolorization in the third day of incubation, coinciding with the maximum laccase activity (260 U/L). The dye was decolorized up to $95 \%$ within 7 days. Laccase levels rose in the dyedecolorizing culture as compared to the maximum activity found in the standard culture $(175 \mathrm{U} / \mathrm{L}$ after $5 \mathrm{~d})$. A generic peroxidase activity with ABTS was also detected in the liquid cultures (maximum activity in 7-9 days), with similar activity values in the absence or presence of the dye (Additional file 1: Figure S1). By contrast, lack or very low ligninolytic peroxidase activities $(<1 \mathrm{U} / \mathrm{L})$ towards $\mathrm{Mn}^{2+}$, veratryl alcohol, Reactive Black 5 or Reactive Blue 19 could be observed.

Next, laccase production was induced with $500 \mu \mathrm{m}$ $\mathrm{CuSO}_{4}$ and $9 \mathrm{~g} / \mathrm{l}$ ethanol, and a maximum of $540 \mathrm{U} / \mathrm{L}$ was reached in three days of culture. The enzyme was purified to homogeneity as shown by a single band between $50-75 \mathrm{kDa}$ in the SDS-PAGE. The exact molecular mass $(67,717 \mathrm{Da})$ and glycosylation degree $(4 \%)$ were determined by MALDI-TOF spectrometry analysis of the pure enzyme before and after deglycosylation. Laccase isolectric point was 6.2. The enzyme showed a typical UV-visible absorption spectrum for a blue laccase, with Absorbance $280 \mathrm{~nm} /$ Absorbance $610 \mathrm{~nm}$ ratio around 21 (Additional file 1: Figure S2). 
The enzyme oxidized typical laccase substrates such as ABTS and 2,6-dimethoxyphenol (DMP) (Table 1), the former, with outstanding catalytic efficiency. Lepthosphaerulina sp. laccase showed common $\mathrm{pH}$ activity profiles for ABTS and DMP, with optimum activity towards ABTS at $\mathrm{pH} 3$ and two peaks of activity at $\mathrm{pH} 3$ and 6 for DMP oxidation (Additional file 1: Figure S3).

The enzymatic decolorization of different types of synthetic organic dyes representative of the most utilized industrial dyes (azo, anthraquinone, indigo and triarylmethane-type dyes) was evaluated by using the purified laccase alone or in the presence of redox mediators. Natural syringyl-type phenolic mediators (namely, acetosyringone, syringaldehyde and methyl syringate) and the artificial mediator 1-hydroxybenzotriazol (HBT) were tested in a molar ratio mediator/dye of 2 . The enzyme was capable of decolorizing roughly $30 \%$ of Aniline Blue and Evans Blue and $15 \%$ of Acid Blue 74 and Methyl Orange (in four hours). These decolorization rates were significantly increased by the presence of S-type phenolic mediators, whereas HBT caused no effect (Table 2). Overall, the decolorization percentages obtained ranged from the nearly absence of decolorization of Orange II, Reactive Black 5 and Remazol Brilliant Blue by laccase alone, to the almost complete decolorization of Orange II, Methyl Orange, Evans Blue or Acid Blue 74 by laccase in the presence of natural mediators. The latter two were decolorized in 1-2 hours (Fig. 1). Over $40 \%$ of Reactive Black 5 was decolorized by the enzyme and acetosyringone or methylsyringate as redox mediators.

By means of trypsin digestion of the purified protein and analysis of the fragmented peptides by nLC/MS-MS, the sequence of one laccase peptide could be disclosed. The peptide, (AK)WGDTIVVNVK, from Leptosphaeria maculans JN3 laccase (Uniprot E4ZMJ1) was found a number of times with high score. No more peptides from the pure protein could be identify in any of the searches made with other public databases, in line with the lack of results obtained from the laccase fingerprinting by MALDI TOF/TOF. Part of the sequence of the laccase peptide (AKWGDTI) was used to design a primer to amplify the laccase sequence from the fungal genome.

\section{Searching for laccase-type MCO genes in Leptosphaerulina sp.}

For the amplification of laccase-like genes from the genomic DNA, we designed degenerate primers based on

Table 1 Kinetic constants for the oxidation of ABTS and DMP by Leptosphaerulina sp. laccase at $\mathrm{pH} 3$

\begin{tabular}{lccc}
\hline & $\mathrm{K}_{m}(\mu \mathrm{M})$ & $\mathrm{k}_{\text {cat }}\left(\mathrm{s}^{-1}\right)$ & $\mathrm{k}_{\text {cat }} / \mathrm{K}_{m}\left(\mathrm{~s}^{-1} \mathrm{mM}^{-1}\right)$ \\
\hline ABTS & $16 \pm 4$ & $630 \pm 47$ & $39,899 \pm 928$ \\
DMP & $197 \pm 50$ & $311 \pm 28$ & $1,579 \pm 214$ \\
\hline
\end{tabular}

Table 2 Decolorization percentages for different synthetic organic dyes obtained by Leptosphaerulina sp. laccase (100 mU) alone or in the presence of acetosyringone (AS), syringaldehyde (SYR), methyl-syringate (MS) or HBT as redox mediators (mediator/ dye ratio $=2$ ) after $4 \mathrm{~h}$ of treatment

\begin{tabular}{lrrrrr}
\hline & Laccase & L-AS & L+SYR & L-MS & L-HBT \\
\hline Methyl orange (azo dye) & 12.8 & 92.2 & 91.5 & 93.1 & 12.0 \\
Reactive Black 5 (di-azo dye) & 3.0 & 41.6 & 17.0 & 41.1 & 2.7 \\
Evans Blue (di azo-dye) & 32.4 & 79.2 & 74.2 & 80.7 & 31.8 \\
Orange II (azo dye) & 2.9 & 80.0 & 48.2 & 83.0 & 2.6 \\
Aniline Blue (triarylmethane dye) & 29.4 & 47.6 & 37.4 & 47.9 & 30.4 \\
Acid Blue 74 (indigo dye) & 16.4 & 90.6 & 91.3 & 91.3 & 17.0 \\
Remazol Brilliant Blue & 2.2 & 20.9 & 56.1 & 15.2 & 1.5 \\
(anthraquinone dye) & & & & &
\end{tabular}

the conserved signature sequences L2 and L3 of laccases from related fungi (L2: G T/S SWYHSH; L3: HP M/L/I HLHGHD F/Y/V). As a result, we amplified the partial sequences of four putative laccase genes from Leptosphaerulina sp. genome (lac1, lac2, lac3 and lac4). The use of the aforementioned laccase peptide-based primer (AKWGDTI) allowed us to enlarge the amplification of lac3 of and of lac4 sequences (upstream L2 motif). However, even though lac4 was also amplified using this primer, only Lac3 contained the exact sequence of the laccase peptide disclosed in the proteomic studies (DTIVVNVK), whereas the sequence of Lac4 was different (DTIVITVN) (Fig. 2).

The amplified partial lac1 sequence (864pb) (GenBank KJ906511) encoded a protein that shared $58 \%$ sequence identity with the partial sequence of Clavariopsis quatica laccase (GenBank ACO07312), whereas the protein

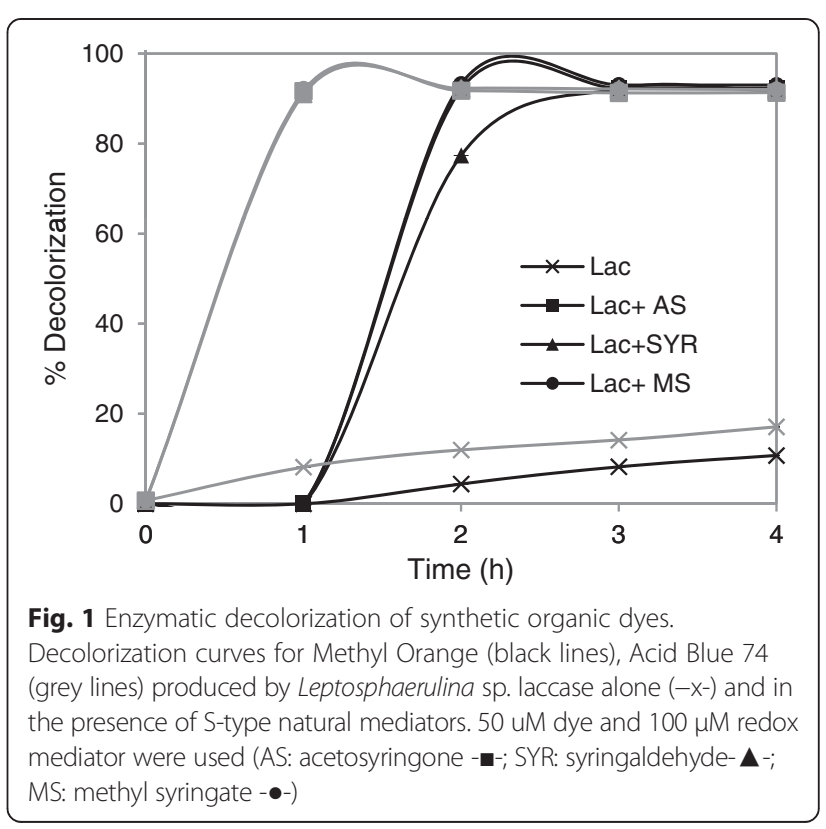




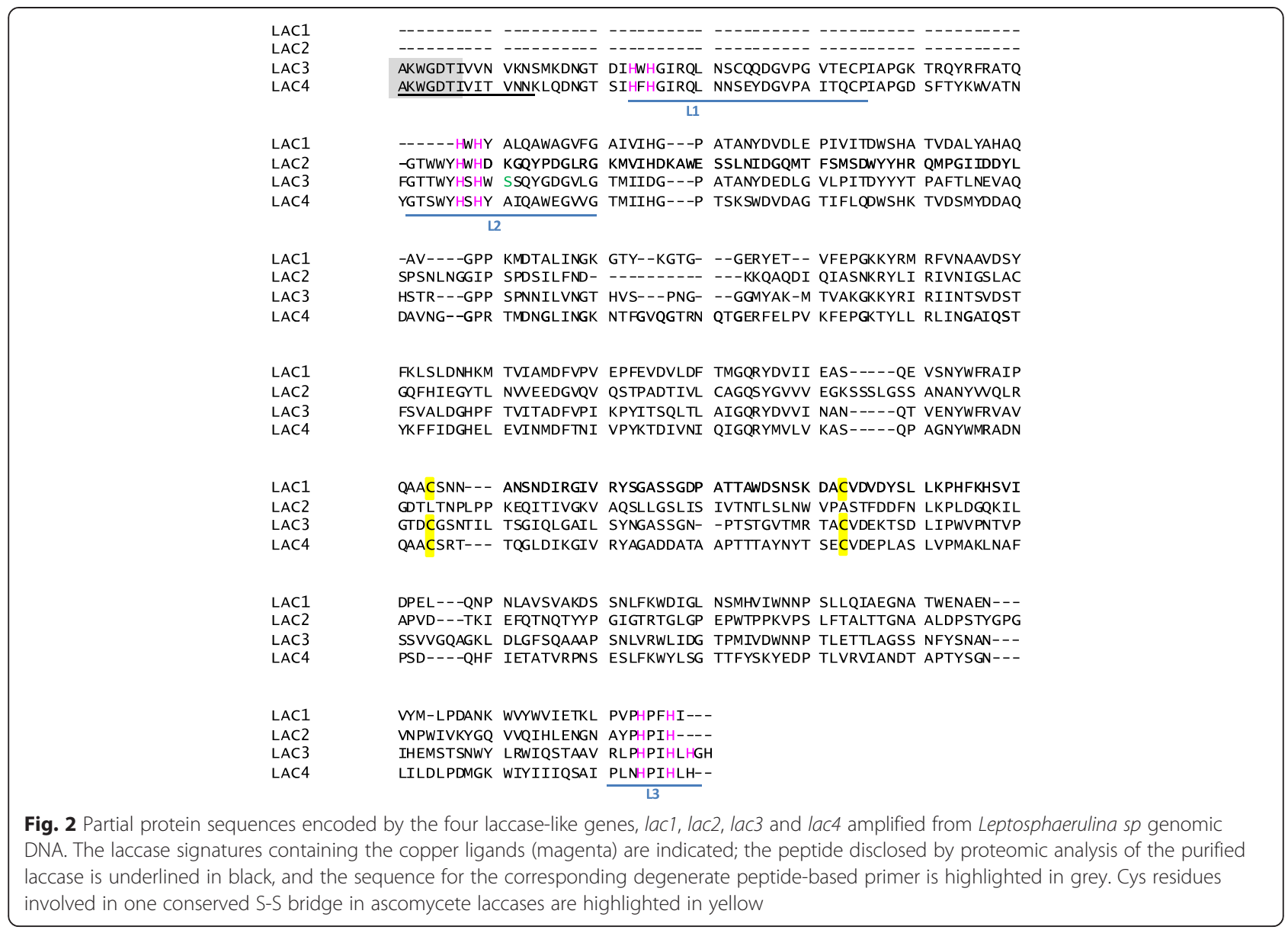

encoded by lac2 (938 pb) (GenBank KJ906512) shared $62 \%$ sequence identity with Stagonospora sp. SAP143 laccase partial sequence (GenBank AAN17289). The Lac3 protein sequence, encoded by lac3 (1074 bp) (GenBank KJ906513), was $71 \%$ identical to the so-called similar to laccase-1 precursor from Leptosphaeria maculans JN3 (NCBI XP_003836225.1 = GenBank CBX92860). Finally, lac4 (1131 bp) (GenBank KJ906514) encoded a protein with $73 \%$ sequence identity with the hypothetical protein SNOG_06494 from Phaeosphaeria nodorum SN15 (XP_ 001796864.1 = GenBank EAT86325). The four hypothetical laccases were not very similar to each other: Lac1 shared $27 \%$ sequence identity with Lac2, 38 \% with Lac3 and $41 \%$ with Lac4.

The phylogenetic analysis of the Leptosphaerulina $s p$ laccase-type MCOs built-in the sequences of known fungal MCOs belonging to different functional families: laccases sensu stricto (basidiomycetous and ascomycetous), fungal pigment MCOs, ferroxidases and ascorbate oxidases (Hoegger et al., 2006). MCO sequences from Pleosporales strains related to Leptosphaerulina, i.e. Leptosphaeria maculans, Pyrenophora tritici-repentis, and Phaeosphaeria
(Stagonospora) nodorum were also included. Overall, 73 fungal sequences and two insect laccases (used to root the tree) were analyzed. The high bootstrap values confirmed robust tree topology. The phylogenetic tree showed Lac1 and Lac4 as the most related sequences among the four Lepthosphaerulina sp proteins. Lac1, Lac4 and Lac3, grouped in the cluster of ascomycete laccases, whereas, Lac2 clearly clustered in a separate group, together with other hypothetical laccase-like proteins, in the cluster of fungal ferroxidases (Fig. 3). No similarities with basidiomycete laccases, fungal ascorbate oxidases or fungal pigment MCOs were found, all of which gathered in differentiated clusters.

\section{Analysis of Leptosphaerulina sp. secretomes}

Crude extracts from dye-decolorizing (7d) and laccaseinduced ( $3 \mathrm{~d}$ ) liquid cultures were concentrated and subjected to proteomic analysis. Laccase activities in the concentrated samples were $882 \mathrm{U} / \mathrm{L}(1.96 \mathrm{U} / \mathrm{mg}$ of the protein content) and $1409 \mathrm{U} / \mathrm{L}(14.09 \mathrm{U} / \mathrm{mg}$ of the protein content), respectively. After precipitation and digestion with trypsin, the extracellular pools of proteins 


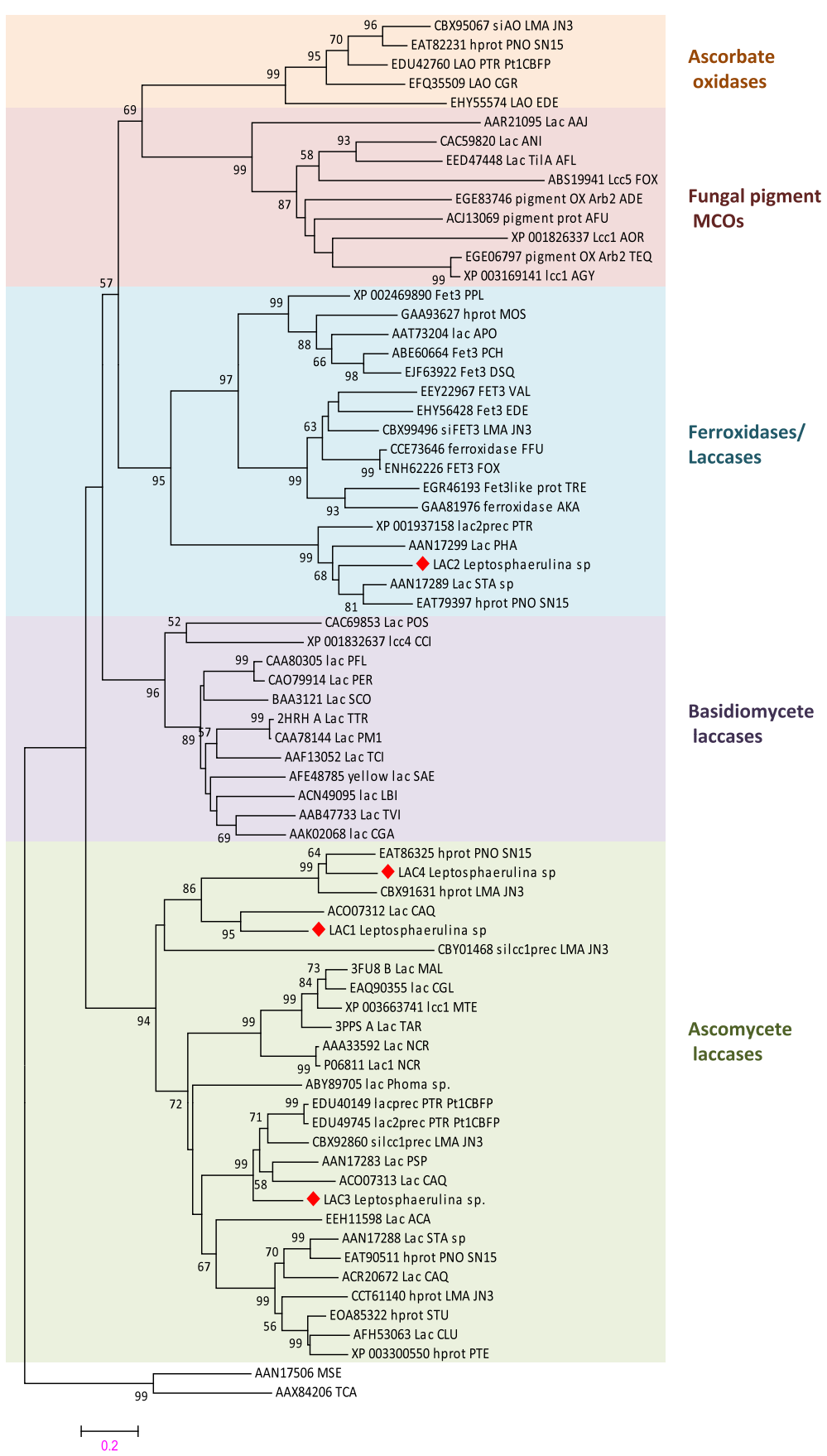

Fig. 3 (See legend on next page.) 
(See figure on previous page.)

Fig. 3 Phylogenetic tree of the four Leptosphaerulina sp. laccase-type proteins and selected fungal laccases, ferroxidases, ascorbate oxidases, and fungal pigment MCOs. The optimal tree constructed by the Neighbor-Joining method based on MUSCLE alignment (L2-L3 sequences length) is shown. Percentages over $50 \%$ of replicate trees in which the associated taxa clustered together in the bootstrap test (1000 replicates) are shown next to the branches. The evolutionary distances were calculated by the JTT matrix-based method. The tree is drawn to scale, with branch lengths in the same units as those of the evolutionary distances used to infer the phylogenetic tree (number of amino acid substitutions per site). All positions containing gaps and missing data were eliminated. Evolutionary analyses were conducted in MEGA6. The GenBank accession numbers for the protein sequences are depicted together with the acronyms for the fungal strains. AAJ: Auricularia auricula-judae; ABE: Arthroderma benhamia; ACA: Ajellomyces capsulatus; ADE: Ajellomyces dermatitidis; AFL: Aspergillus flavus; AFU: Aspergillus fumigatus; AGY: Arthroderma gypseum; AKA: Aspergillus kawachii; ANI: Aspergillus nidulans; AOR: Aspergillus onzzae; APO: Auricularia polytricha; CAQ: Clavariopsis aquatica; CCl: Coprinopsis cinerea; CGA: Coriolopsis gallica; CGL: Chaetomium globosum; CGR: Colletotrichum graminicola; CLU: Curvularia lunata; DSQ: Dichomitus squalens; EDE: Exophiala dermatitidis; FFU: Fusarium fujikuroi; FOX: Fusarium oxysporum; LMA: Lepthospaheria maculans; MAL: Melanocarpus albomyces; MOS: Mixia osmundae; MTH: Myceliophtora thermophila; NCR: Neurospora crassa; PCH: Phanerochaete chrysosporium; PER: Pleurotus enyngii; PFL: Pleurotus florida; PNO: Phaeosphaeria nodorum; PSP: Phaeosphaeria spartinicola; PTE: Pyrenophora teres; PTR: Pyrenophora tritici-repentis; SAE: Stropharia aeruginosa; SCO: Schizophyllum commune; STA: Stagonospora sp.; STU: Setosphaeria turcica; TAR: Theilavia arenaria; TEQ: Trichophyton equinum; TCl: Trametes cinnabarina; TVl: Trametes villosa; POS: Pleurotus ostreatus; TRE: Trichoderma reesei; TTR: Trametes trogii; LBI: Lacaria bicolor; PHA: Phaeosphaeria halima; PPL: Postia placenta; VAL: Verticillium alfalfae. The tree was rooted by two insect laccase sequences from Manduca sexta (MSE) and Tribolium castaneum (TCA)

(EPP) were analyzed by nLC-ion trap mass spectrometry and protein homologous to predicted oxidoreductases deposited in public databases were searched.

Overall, homologous proteins to diverse types of oxidoreductases, peroxidases, flavo-oxidases, and coppercontaining metalloproteins, were found in the shotgun analyses of both samples (Fig. 4). Flavo-oxidase likeproteins were the most abundant of the oxidoreductases found in the secretome of dye-decolorizing culture, in

\section{A. Dye-decolorizing culture- Uniprot (415)}

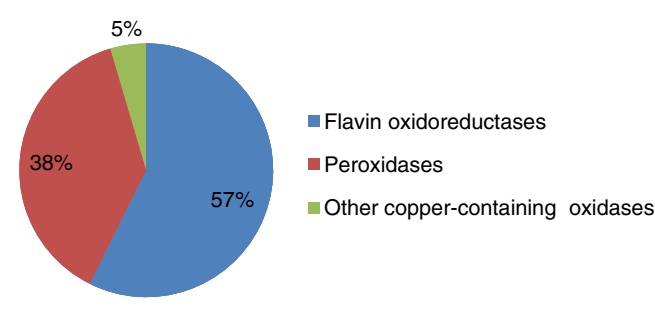

\section{B. Laccase-induced culture- Uniprot (194)}

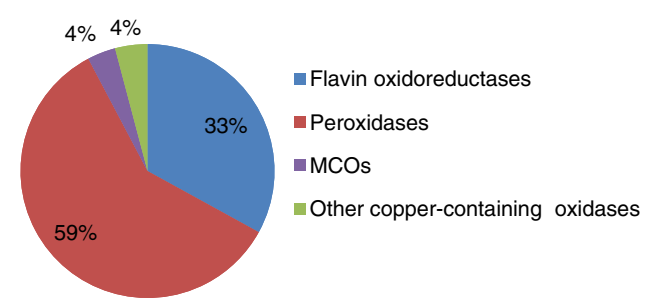

Fig. 4 Relative abundance of the different types of oxidoreductases found in the secretomes of Leptosphaerulina sp. Flavin oxidoreductases (GMC oxidases, NADH oxidases and others), peroxidases (POD, DyPs, catalases), MCOs and other copper-containing oxidases from the nLCMS-MS analysis and search against Uniprot database (restricted to Ascomycota) are depicted. a. dye-supplemented culture. b. Laccaseinduced culture. The total number of oxidoreductase matches is shown in parenthesis (see Additional file 1: Tables S1 and S2 for detailed information) particular, oxidases from the Glucose-Methanol-Choline (GMC) oxidoreductase family and NADH oxidases. Most peroxidases identified by the shotgun analyses of both samples corresponded to catalase-peroxidases type. Besides, in the laccase induced culture, matching peptides from a lignin peroxidase and a dye-decolorizing peroxidase could also be found. A small percentage of copper-containing enzymes homologous to glyoxal oxidase, galactose oxidase or amine oxidase were also found in both secretomes. The most significant hits from the search against Uniprot database of the EPPs from Leptosphaerulina sp. grown in dye-supplemented and laccaseinduced cultures are summarized in Additional file 1: Tables S1 and S2, respectively. Regarding MCOs, the aim of our study, homologous proteins could only be found in the laccase-induced sample (Fig. 4). Again, the unique peptide from Leptosphaeria maculans JN3 laccase (Uniprot E4ZMJ1), already found in the nLC-MS/MS analysis of the pure enzyme (AKWGDTIVVNVK), was repeatedly identified (see Additional file 1: Table S2).

Since the search against Uniprot database rendered scarce MCO hits, we focussed on the quest against the specific database LccED. More to the point, the presence in both EPPs of the four Lepthosphaerulina sp. laccases was investigated using a purpose-built database. The top10 extracellular MCOs of both secretomes (identified in the searches against LccED and the in-house database) are jointly summarized in Tables 3 and 4. The protein E5Q_00271 from Mixia osmundae (GAA93627) was repeatedly found in both secretomes in the search against LccED. In fact, the sole MCO certainly found in the EPP from the dye-decolorizing culture was the protein homologous to E5Q 00271 (Table 3). This fungal protein presents a typical MCO sequence with the three typical cupredoxin domains containing the four conserved copper binding motifs (L1-L4). More in particular, it holds the typical constellation of acidic residues of ferroxidase 
Table 3 Top-10 extracellular MCOs from the shotgun analysis of Lepthosphaerulina sp. secretome of the dye-decolorizing culture, identified in the searches against LCCED and the in house database

\begin{tabular}{|c|c|c|c|c|c|}
\hline Homologous to predicted proteins & GenBank accession number & Score & Coverage & Unique peptides & PSMs \\
\hline Hypothetical [Mixia osmundae IAM 14324] & GAA93627 & 769.2 & 8.41 & 5 & 211 \\
\hline Putative multicopper oxidase [Saccharomonospora marina XMU15] & EHR52757 & 2.7 & 6.08 & 1 & 1 \\
\hline MCO type 2 (Bilirubin oxidase) [Intrasporangium calvum] & ADU47440 & 2.4 & 1.96 & 1 & 1 \\
\hline Bilirubin oxidase [Haliangium ochraceum] & ACY16794 & 2.3 & 1.82 & 1 & 1 \\
\hline Ascorbate oxidase-like [Glycine max] & 356549511 & 2.1 & 1.22 & 1 & 1 \\
\hline Multicopper oxidase, putative [Ricinus communis] & EEF35106.1 & 2.0 & 1.17 & 1 & 1 \\
\hline Lac3 Lepthosphaerulina sp. & _- & 26.5 & 10.33 & 2 & 7 \\
\hline
\end{tabular}

sequences and it is close similar to that of $P$. chrysosporium Fe3p (ABE60664). In fact, in the phylogenetic analysis, this $\mathrm{MCO}$ sequence grouped with the abovementioned Fe3p and similar sequences in the ferroxidase cluster (see Fig. 2).

On the other hand, in the laccase-induced secretome, the search against LccED revealed the profuse finding of the same peptide from L. maculans laccase CBX92860 (=Uniprot E4ZMJ1) previously identified in the isolated laccase and found in Lac3 sequence (71 \% identical to $L$. maculans laccase). Moreover, several unique peptides of Lac3 were recurrently found in the laccase-induced secretome using the in-house database (Table 4). Lac2 was also found in this secretome sample, and Lac1 in much lesser extent, whereas no peptides from Lac4 could be detected in the EPP from the laccase-induced culture (Table 4). On the other hand, Lac3 was the sole Leptosphaerulina sp. laccase identified in the dye-decolorizing secretome (Table 3). Finally, up to 11 unique peptides from Lac3 (including the peptide AKWGDTIVVNVK) were repeatedly found during the analysis of the isolated laccase when using the in-house database. Quite the opposite, not a single peptide from Lac1, Lac2 or Lac4 could be found in this sample. All these pieces of evidence confirmed Lac3 as the main laccase isoenzyme purified and characterized in this study.

\section{Discussion}

\section{Lac3, a sensu-stricto laccase}

The properties of the enzyme purified from the laccaseinduced culture, which happened to be Lac3, strictly corresponded to the biochemical and kinetic properties of a typical fungal laccase. It is a monomeric glycoprotein, with molecular mass around $70 \mathrm{kDa}$.

Lac3 efficiently oxidizes common laccase substrates such as ABTS and DMP with high catalytic efficiency regarding other fungal laccases [17-20]. On the contrary, it was not able to oxidize HBT in an efficient manner, as shown by the similar decolorization rates obtained with or without HBT as mediator. Lac3 apparently holds a low-medium redox potential typical of most ascomycete laccases such as Myceliophtora thermophila laccase, which is also unable to oxidize this synthetic mediator (with redox potential above $+1 \mathrm{~V}$ ) [21]. Conversely, the oxidation of the syringyl-type phenolic compounds is facilitated by their lower redox potential (around $+0.6 \mathrm{~V}$ ) as occurred for ABTS.

Table 4 Top-10 extracellular MCOs from the shotgun analysis of Lepthosphaerulina sp. secretome of laccase-induced culture, identified in the searches against LCCED and the in house database

\begin{tabular}{|c|c|c|c|c|c|}
\hline Homologous to predicted proteins & GenBank accession number & Score & Coverage & Unique peptides & PSMs \\
\hline Hypothetical [Mixia osmundae IAM 14324] & GAA93627 & 1217 & 7.44 & 4 & 287 \\
\hline Similar laccase-1 precursor [Leptosphaeria maculans JN3] & CBX92860 & 842.7 & 2.08 & 2 & 315 \\
\hline Blue copper oxidase cueO precursor [Pyrenophora tritici-repentis Pt-1C-BFP] & EDU50675 & 26.4 & 2.40 & 2 & 8 \\
\hline MCO hypothetical protein [Meyerozyma guilliermondii ATCC 6260] & EDK39262 & 23.1 & 4.37 & 1 & 8 \\
\hline MCO [Podospora anserina] & CAP61936 & 12.6 & 1.28 & 1 & 5 \\
\hline Bilirubin oxidase precursor [Neurospora crassa OR74A] & EAA27114 & 7.0 & 1.38 & 1 & 3 \\
\hline Laccase [Xylaria polymorpha] & ABV32571 & 6.3 & 5.39 & 1 & 3 \\
\hline Lac1 Lepthosphaerulina sp. & - & 7.0 & 11.90 & 2 & 2 \\
\hline Lac2 Lepthosphaerulina sp. & - & 313 & 44.48 & 14 & 78 \\
\hline Lac3 Lepthosphaerulina sp. & _ & 1747 & 47.28 & 8 & 478 \\
\hline
\end{tabular}

Score, sum of the scores of the individual peptides; Coverage, percentage of the protein sequence covered by identified peptides; PSM, total number of identified peptide sequences (peptide spectrum matches), including those redundantly identified 
Lac3 was able to decolorize several synthetic organic dyes, but Reactive Black 5 (and others) could not be directly oxidized by the enzyme mainly due to its high redox potential (about $+1.3 \mathrm{~V}$ ). Overall, the enzymatic decolorization of the dyes was notably promoted (up to $90 \%$ ) by the presence of the lignin-derived compounds, as described for basidiomycetous laccases [22]. Yet, once oxidized by the enzyme, the competence of the phenoxyl radicals of the S-type compounds to act as redox mediators depends on the chemical structure of the dye and its redox potential. Recently, it has been described the degradation of chlorophenols and chloranilines by a laccase from Leptosphaerulina chartarum using guiacol as redox mediator [12]. The use of natural mediators notably enhances the applicability of these low-medium-redox potential laccases as biotechnological tools in the modern biorefineries [23]. Besides, ascomycete laccases are more easily expressed than basidiomycete laccases in Aspergillus or yeast as heterologous hosts, being more prone to protein engineering by directed evolution [24].

\section{Genomic approach}

The composition of MCOs in the different species might vary according to their lifestyle [25], although multiplicity events within the different type of genes frequently makes not easy to identify the connection of gene distribution to the fungal lifestyle [26]. To date, phylogenetic studies on laccases and related MCOs have revealed their grouping in functional clusters $[3,26]$. In general, fungal laccases can be divided into ascomycetous and basidiomycetous clades [25] although the phylogenetic classification of some laccases does not strictly follow the species phylogeny $[27,28]$. In this study, known ascomycete laccases, basidiomycete laccases, fungal ferroxidases, fungal ascorbate oxidases and fungal pigment MCOs, including MCO sequences from Pleosporales strains related to Leptosphaerulina, were used to construct the phylogeny of the four Leptosphaerulina MCOs. The well known laccases from white-rot basidiomycetes such as Trametes villosa, Pleurotus ostreatus, Coriolopsis gallica, Trametes trogii, etc., jointly grouped in one separate cluster. A second cluster contained characterized ascomycete laccases such as those from Myceliphthora thermophila, Melanocarpus albomyces, Thielavia arenaria or Neurospora crassa, together with other ascomycete hypothetical laccase sequences from the Pleosporales strains. Lac1, Lac3 and Lac4 from Leptosphaerulina sp., gathered in this cluster, thus evidencing their matching with the species phylogeny. Of the three sequences, Lac3 was the most closely related to the well characterized ascomycete laccases, suggesting it is a sensu-stricto laccase as it was confirmed by the biochemical characterization of the purified laccase. Moreover, Lac1, Lac3 and Lac4 partial sequences hold two Cys residues involved in one conserved S-S bridge in ascomycete laccases (C298-C332 in PDB 1GW0, Melanocarpus albomyces laccase) (see Fig. 3).

On the other hand, Lac2 rooted apart from laccases sensu-stricto, in the same node than ferroxidases, together with other hypothetical laccases from the related Pleosporales strains. Fungal ferroxidases such as Fet3p play a key role in iron metabolism and they are supposed to play a protective role by suppressing copper and iron cytotoxicity. Fet3 proteins hold three acidic residues, one glutamate and two aspartates (E185, D283 and D409 in S. cerevisiae Fet3p), near the CuT1 site which constitutes the iron binding site [29]. Besides, the disposition of negatively charged residues at the protein surface presumptively make feasible $\mathrm{Fe}^{3+}$ translocation to the permease Ftr1 through a pathway under electrostatic guidance [30]. When comparing the partial sequences of Lac2 or the laccase from Phaeosphaeria halima (AAN17299) with typical Fet3 proteins no such a collection of acidic residues could be observed. In fact, after modeling Lac2 with 1ZPU (Fet3p) as template, no iron binding site could be observed (data not shown). The position of the three acidic residues were occupied by two Asn and one Pro residues in Lac2, whereas the Tyr 354 residue, supposed to be conserved in ferroxidases [31], was replaced by Arg. The ferroxidase activity of Lac2 is therefore questioned by the lack of the typical ferroxidase residues. This cluster may meet classical (Fet3-type) ferroxidases, ferroxidases with some laccase activity - and other non sensu-stricto laccase-like proteins with perhaps some hybrid activities, as described previously [26].

\section{Proteomic approach}

It is well known that laccase expression is regulated by an array of factors not merely concerned to the transcription level. The synthesis and secretion of laccases are severely influenced by the culture conditions, nutrient levels, fungal development stage and the presence of metal ions and aromatic compounds as inducers [32]. During the time course study of Leptosphaerulina sp. grown in liquid culture we observed an increment of laccase activity by the presence of the aromatic dye Reactive Black 5, in concordance with reported induction of laccase by organic dyes [33]. The secretion of Lac3 during dye-decolorization by the fungus was demonstrated during the shotgun analysis of the pool of proteins secreted under these conditions. However, Lac3 was not as abundant as it could be expected, in part because the time of collecting the sample (7d) did not correspond to the maximum laccase activity (3d).

Laccase production was significantly induced by the presence of $\mathrm{Cu}^{2+}$ and ethanol, making feasible the detection of Lac1-Lac3 in the secretome. The transcription of 
laccase genes is regulated by the presence of response elements in the laccase promoters such as MREs (Metal Responsive Element) and STREs (Stress responsive element) $[32,34,35]$. Besides the rapid effect of copper on the induction of transcription of laccase genes [36], $\mathrm{Cu}^{2+}$ might impair laccase degradation by proteases [37]. Conversely, ethanol improves laccase secretion by fungi [38] and might induce the expression of chaperones involved in protein folding and secretion [39]. The presence of different peaks of activity in time for induced (3d) and not induced cultures (5d) may suggest the occurrence of constitutive and inducible laccases in Leptosphaerulina sp [40-42].

Lac3, a sensu-stricto laccase, was the main laccase-type protein secreted by Leptosphaerulina sp. The role of laccases in pathogenic fungi could improve their virulence towards plants by inactivation of otherwise toxic phytoalexins or phenolics [43]. Conversely, laccase might be essential for pathogenicity by the melanization of the appressoria necessary for the penetration of the host, as described for Colletotrichum orbiculare (cucumber anthracnose) or Metarhizium anisopliae (an insect pathogenic fungi) [44, 45]. On the other hand, Lac2, a ferroxidase/laccase protein was also abundantly present in the secretome from laccase-induced culture. Peptides homologous to those from Pyrenophora tritici-repentis $\mathrm{CueO}$ were also identified in the laccase-induced sample. Besides, the ferroxidase-type protein E5Q_00257 from Mixia osmundae IAM 14324 was recurrently found in both dye-decolorizing and laccase-induced EPPs. This enigmatic fungus, the only species currently known in class Mixiomycetes, is an intracellular parasite of ferns (Osmunda L) in which it causes small yellow to brown leaf spots [46]. Iron acquisition is a critical aspect of the virulence of many pathogenic microbes. Next to its function in iron metabolism, it has been suggested a protective role for Fet3p by suppressing copper and iron cytotoxicity [47].

It is remarkable the profusion of oxidases suppliers of hydrogen peroxide in fungi. Alcohol-oxidase-type flavooxidases [48] and copper-containing enzymes like glyoxal oxidase or galactose oxidase were abundantly present in Leptosphaerulina sp. secretomes. NADH oxidases, responsible for superoxide production and cell differentiation in fungi [49] were also frequently found. All of them may play a central role in the cycling and bioavailability of metals and carbon in the natural systems. Conversely, the significant occurrence of catalase-peroxidases in plant pathogenic fungi would be driven by the need of $\mathrm{H}_{2} \mathrm{O}_{2}$ detoxification to deal with the host oxidative burst [50].

\section{Conclusions}

Of the four laccase-type MCO genes found in Leptosphaerulina sp., three (lac1, lac3 and lac4) encode for ascomycete laccase-like proteins, whereas Lac2 is related to ferroxidases/laccases proteins. The purification and characterization of Lac3, the main laccase produced by Leptosphaerulina sp. in dye decolorizing and laccaseinduced cultures, allowed us to confirm that it is a sensu-stricto laccase with high oxidation efficiency towards ABTS and phenolic compounds. Moreover, the enzyme is able to decolorize synthetic organic dyes with high efficiency in the presence of natural phenolic mediators. These results show the way for searching for laccase-type MCOs, with possible biotechnological interest, in fungal families where the presence or function of these enzymes is poorly known. The information provided by the use of genomic and proteomic tools must be combined with classical biochemical studies since only a precise characterization of the enzyme can prove its predicted catalytic activity and confirm its potential applicability.

\section{Additional file}

Additional file 1: Table S1. Oxidoreductases identified from the secretome of Leptosphaerulina sp. grown in dye-supplemented culture (7d). Only significant hits identified from the shotgun nLC/MS-MS analysis of the entire EPP after search against Uniprot Ascomycota database are shown. Protein identities provided on the basis of a single matching peptide, were considered as tentative. Table S2. Oxidoreductases identified from the secretome of Leptosphaerulina sp. grown in the laccase-induced culture (3d). Only significant hits identified from the shotgun nLC/MS-MS analysis of the entire EPP after search against Uniprot Ascomycota database are shown. Protein identities provided on the basis of a single matching peptide, were considered as tentative. Figure S1. Laccase $(-)$ and peroxidase (-) activities with ABTS detected in Leptosphaerulina. sp. standard liquid culture (black lines), dye-supplemented culture (red lines) and laccaseinduced culture with CuSO4 and ethanol (blue lines). Figure S2. Biochemical characterization of the purified laccase from Leptosphaerulina sp. MALDI-TOF spectrometry analysis of the native and deglycosylated protein (A); SDSPAGE and Coomassie Blue staining (B); UV-Vis absorbance spectrum (C). Figure S3. Optimum pH for oxidation of ABTS (A) and 2,6-dimethoxyphenol (B) by Leptosphaerulina sp. laccase. (PDF $190 \mathrm{~kb}$ )

\section{Competing interests}

The authors declare that they have no competing interests exist.

\section{Authors' contributions}

SC conceived the study. SC and JB designed the experiments. LSC and XC carried on the experimental work. MFL carried out the nLC-MS-MS analysis. LSC, XC and SC drafted the manuscript. JB, MJM, and SC revised the manuscript. All authors read and approved the final manuscript.

\section{Acknowledgments}

This research was supported by the Program for Interuniversity Cooperation and Scientific Reasearch (PCI) from the Spanish Agency for International Cooperation and Development (AECID), Project AP/033932/11, and the Spanish Project NOESIS BIO2014-56388-R. L.S. Copete and X. Chanagá thank Amanda L. Mora and María S. Yepes for their support and Universidad Nacional de Colombia, Sede Medellín, for short-term fellowships.

\section{Author details}

${ }^{1}$ Centro de Investigaciones Biológicas, CSIC. Ramiro de Maeztu 9, Madrid 28040, Spain. ${ }^{2}$ PROBIOM, Universidad Nacional de Colombia Sede Medellín, Calle 59a No 63-20, Medellín, Colombia. ${ }^{3}$ Present address: Universidad Manuela Beltrán, Calle de los Estudiantes 10-20, Bucaramanga, Colombia. 
Received: 14 April 2015 Accepted: 29 July 2015

\section{Published online: 14 August 2015}

\section{References}

1. Nakamura K, Go N. Function and molecular evolution of multicopper blue proteins. Cell Mol Life Sci. 2005;62:2050-66.

2. Levasseur A, Saloheimo M, Navarro D, Andberg M, Pontarotti P, Kruus K, et al. Exploring laccase-like multicopper oxidase genes from the ascomycete Trichoderma reesei: a functional, phylogenetic and evolutionary study. BMC Biochem. 2010;11:32.

3. Tamayo Ramos JA, Barends S, Verhaert RMD, de Graaff LH. The Aspergillus niger multicopper oxidase family: analysis and overexpression of laccase-like encoding genes. Microb Cell Fact. 2011;10:78.

4. Kues U, Liu Y. Fruiting body production in basidiomycetes. Appl Microbiol Biotechnol. 2000;54:141-52

5. Zhu XD, Gibbons J, GarciaRivera J, Casadevall A, Williamson PR. Laccase of Cryptococcus neoformans is a cell wall- associated virulence factor. Infect Immun. 2001;69:5589-96.

6. Holker U, Dohse J, Hofer M. Extracellular laccases in ascomycetes Trichoderma atroviride and Trichoderma harzianum. Folia Microbiol Prague. 2002;47:423-7.

7. Kellner $H$, Luis $P$, Buscot F. Diversity of laccase-like multicopper oxidase genes in Morchellaceae: identification of genes potentially involved in extracellular activities related to plant litter decay. FEMS Microbiol Ecol. 2007;61:153-63.

8. Liers C, Arnstadt T, Ullrich R, Hofrichter M. Patterns of lignin degradation and oxidative enzyme secretion by different wood- and litter-colonizing basidiomycetes and ascomycetes grown on beech-wood. FEMS Microbiol Ecol. 2011;78:91-102.

9. Abler SW. Ecology and Taxonomy of Leptosphaerulina spp. Associated with Turfgrasses in the United States. Thesis 2003. Faculty of the Virginia Polytechnic Institute and State University.

10. Rouxel T, Grandaubert J, Hane JK, Hoede C, van de Wouw AP, Couloux A, et al. Effector diversification within compartments of the Leptosphaeria maculans genome affected by Repeat-Induced Point mutations. Nat Commun. 2011;2:202.

11. Chanagá X, Escobar JP, Marín M, Yepes MS. Native fungi with industrial dye degrading potential in the Aburrá valley, Colombia. Revista Facultad Nacional de Agronomía Medellín. 2012;65(2):6811-21.

12. Simon LT, Bishop DS, Hooper GR. Ultrastructure and CytochemicalLocalization of Laccase in 2 Strains of Leptosphaerulina-Briosiana (Pollaci) Graham and Luttrell. J Bacteriol. 1979;137:537-44.

13. Sajben-Nagy E, Manczinger L, Škrbić B, Živančev J, Antić I, Krisch J, et al. Characterization of an extracellular laccase of Leptosphaerulina chartarum. World J Microbiol Biotechnol. 2014;30(9):2449-58.

14. Guillén F, Martínez AT, Martínez MJ. Substrate specificity and properties of the aryl-alcohol oxidase from the ligninolytic fungus Pleurotus eryngii. Eur J Biochem. 1992;209:603-11.

15. Stoscheck CM. Protein assay sensitive at nanogram levels. Anal Biochem. 1987;160:301-5.

16. Kall L, Canterbury JD, Weston J, Noble WS, MacCoss MJ. Semi-supervised learning for peptide identification from shotgun proteomics datasets. Nat Methods. 2007:4:923-5.

17. Cusano AM, Mekmouche Y, Meglecz E, Tron T. Plasticity of laccase generated by homeologous recombination in yeast. FEBS J. 2009;276:5471-80.

18. Maté D, García-Burgos C, García-Ruiz E, Ballesteros A, Camarero S, Alcalde M. Laboratory evolution of high redox potential laccases. Chem Biol. 2010;17:1030-41

19. Camarero S, Pardo I, Cañas Al, Molina P, Record E, Martínez AT, et al. Engineering platforms for directed evolution of laccase from Pycnoporus cinnabarinus. Appl Environ Microbiol. 2012;78:1370-84.

20. Mate D, García-Ruiz E, Camarero S, Shubin V, Falk M, Shleev S, et al. Switching from blue to yellow: Altering the spectral properties of a high redox potential laccase by directed evolution. Biocatal Biotransform. 2013;31:8-21.

21. Ibarra D, Romero J, Martínez MJ, Martínez AT, Camarero S. Exploring the enzymatic parameters for optimal delignification of eucalypt pulp by laccase-mediator. Enzyme Microb Technol. 2006;39:1319-27.

22. Camarero S, Ibarra D, Martínez MJ, Martínez AT. Lignin-derived compounds as efficient laccase mediators for decolorization of different types of recalcitrant dyes. Appl Environ Microbiol. 2005;71:1775-84.
23. Camarero S, Martínez MJ, Martínez AT. Understanding lignin biodegradation for the improved utilization of plant biomass in modern biorefineries. Biofuels Bioprod Biorefining. 2014;8(5):615-25.

24. Pardo I, Camarero S. Laccase engineering by rational and evolutionary design Cell. Mol Life Sci. 2015;72:897-910.

25. Hoegger PJ, Kilaru S, James TY, Thacker JR, Kües U. Phylogenetic comparison and classification of laccase and related multicopper oxidase protein sequences. FEBS J. 2006;273:2308-26.

26. Kues U, Ruhl M. Multiple Multi-Copper Oxidase Gene Families in Basidiomycetes - What for? Curr Genomics. 2011;12:72-94.

27. Floudas D, Binder M, Riley R, Barry K, Blanchette RA, Henrissat B, et al. The Paleozoic Origin of Enzymatic Lignin Decomposition Reconstructed from 31 Fungal Genomes. Science. 2012;336(6089):1715-9.

28. Fan $X Z$, Zhou $Y$, Xiao $Y, X u Z Y$, Bian $Y B$. Cloning, expression and phylogenetic analysis of a divergent laccase multigene family in Auricularia auricula-judae. Microbiol Res. 2014;169:453-62.

29. Stoj CS, Augustine AJ, Zeigler L, Solomon El, Kosman DJ. Structural basis of the ferrous iron specificity of the yeast ferroxidase, Fet3p. Biochemistry. 2006:45:12741-9.

30. di Patti MCB, Pascarella S, Catalucci D. Calabrese L Homology modeling of the multicopper oxidase Fet3 gives new insights in the mechanism of iron transport in yeast. Protein Eng. 1999;12:895-7.

31. Larrondo LF, Salas L, Melo F, Vicuña R, Cullen D. A novel extracellular multicopper oxidase from Phanerochaete chrysosporium with ferroxidase activity. Appl Environ Microbiol. 2003;69:6257-63.

32. Piscitelli A, Giardina P, Lettera V, Pezzella C, Sannia G, Faraco V. Induction and Transcriptional Regulation of Laccases in Fungi. Curr Genomics. 2011;12:104-12

33. Vanhulle S, Enaud E, Trovasle M, Nouaimeh N, Bols CM, Keshavarz T, et al. Overlap of laccases/cellobiose dehydrogenase activities during the decolourisation of anthraquinonic dyes with close chemical structures by Pycnoporus strains. Enzyme Microb Technol. 2007:40:1723-31.

34. Collins PJ, Dobson ADW. Regulation of laccase gene transcription in Trametes versicolor. Appl Environ Microbiol. 1997;63:3444-50.

35. Alves AM, Record E, Lomascolo A, Scholtmeijer K, Asther M, Wessels JG, et al. Highly efficient production of laccase by the basidiomycete Pycnoporus cinnabarinus. Appl Environ Microbiol. 2004;70:6379-84.

36. Kim HI, Kwon OC, Kong WS, Lee CS, Park YJ. Genome-Wide Identification and Characterization of Novel Laccase Genes in the White-Rot Fungus Flammulina velutipes. Mycobiology. 2014;42(4):322-30.

37. Palmieri G, Bianco C, Cennamo G, Giardina P, Marino G, Monti M, et al. Purification, characterization, and functional role of a novel extracellular protease from Pleurotus ostreatus. Appl Environ Microbiol. 2001;67:2754-9.

38. Lee IY, Jung $\mathrm{KH}$, Lee $\mathrm{CH}$, Park YH. Enhanced production of laccase in Trametes vesicolor by the addition of ethanol. Biotechnol Lett. 1999;21:965-8.

39. van de Laar T, Visser C, Holster M, Lopez CG, Kreuning D, Sierkstra L, et al. Increased heterologous protein production by Saccharomyces cerevisiae growing on ethanol as sole carbon source. Biotechnol Bioeng. 2007;96:483-94.

40. Muñoz C, Guillén F, Martínez AT, Martínez MJ. Induction and characterization of laccase in the ligninolytic fungus Pleurotus eryngit. Curr Microbiol. 1997;34:1-5.

41. Palmieri G, Giardina P, Bianco C, Fontanella B, Sannia G. Copper induction of laccase isoenzymes in the ligninolytic fungus Pleurotus ostreatus. Appl Environ Microbiol. 2000;66:920-4.

42. da Cunha MA A, Barbosa AM, Giese EC, Dekker RFH. The effect of carbohydrate carbon sources on the production of constitutive and inducible laccases by Botryosphaeria sp. J Basic Microb. 2003;43:385-92.

43. Marbach I, Harel E, Mayer AM. Pectin, A 2Nd Inducer for Laccase Production by Botrytis-Cinerea. Phytochemistry. 1985;24:2559-61.

44. Lin SY, Okuda S, Ikeda K, Okuno T, Takano Y. LAC2 Encoding a Secreted Laccase Is Involved in Appressorial Melanization and Conidial Pigmentation in Colletotrichum orbiculare. Mol Plant Microbe Interact. 2012;25(12):1552-61.

45. Fang W, Fernandes EKK, Roberts DW, Bidochka MJ, St Leger RJ. A laccase exclusively expressed by Metarhizium anisopliae during isotropic growth is involved in pigmentation, tolerance to abiotic stresses and virulence. Fungal Genet Biol. 2010;47:602-7.

46. Nishida H, Nagatsuka Y, Sugiyama J. Draft genome sequencing of the enigmatic basidiomycete Mixia osmundae. J Gen Appl Microbiol. 2011;57:63-7. 
47. Stoj C, Kosman DJ. Cuprous oxidase activity of yeast Fet3p and human ceruloplasmin: implication for function. FEBS Lett. 2003;554:422-6.

48. Goswami P, Chinnadayyala SS, Chakraborty M, Kumar AK, Kakoti A. An overview on alcohol oxidases and their potential applications. Appl Microbiol Biotechnol. 2013;97:4259-75.

49. Hansel CM, Zeiner CA, Santelli CM, Webb SM. Mn(II) oxidation by an ascomycete fungus is linked to superoxide production during asexual reproduction. Proc Natl Acad Sci U S A. 2012:109:12621-5.

50. Tanabe S, Ishii-Minami N, Saitoh Kl, Otake Y, Kaku H, Shibuya N, et al. The role of catalase-peroxidase secreted by Magnaporthe oryzae during early infection of rice cells. Mol Plant-Microbe Interact. 2011;24:163-71.

\section{Submit your next manuscript to BioMed Central} and take full advantage of:

- Convenient online submission

- Thorough peer review

- No space constraints or color figure charges

- Immediate publication on acceptance

- Inclusion in PubMed, CAS, Scopus and Google Scholar

- Research which is freely available for redistribution 